\title{
Pneumococcal vaccine available in Kenya through AMC
}

Kenya is to receive GlaxoSmithKline's pneumococcal vaccine, Synflorix, through the Advance Market Commitment (AMC), a scheme designed to provide children living in the world's poorest countries with heavily discounted vaccines.

The AMC, backed by five donor countries (the UK, Canada, Russia, Norway and Italy) and the Bill \& Melinda Gates Foundation, guarantees the availability of initial purchase funds and allows companies to invest in vaccine development and manufacturing. Combined with the high volume needs, companies can then reduce vaccine cost.

Synflorix is the first vaccine to be supplied via the AMC in Africa, and Kenya has already started immunising children. Through the AMC, GlaxoSmithKline and Pfizer have signed 10-year contracts to provide up to 300 million doses each of their pneumococcal vaccines, at $\approx 90 \%$ discount of the cost in developed markets.

The Global Alliance for Vaccines and Immunisation expects that by 2015, more than 40 developing countries will have received pneumococcal vaccines through the AMC.

GlaxoSmithKline. First African country introduces GSK's pneumococcal vaccine through innovative financing mechanism. Media Release : 11 Feb 2011. Available from: URL: http://www.gsk.com 